\title{
Performance Cycle Analysis on Turbo Fan Engine PW4000
}

\author{
Shray Benawra ${ }^{1}$, Jiqiang Wang ${ }^{1,2}$, Hong Yue ${ }^{3}$, Georgi Dimirovsky ${ }^{4}$ \\ 1. Jiangsu Province Key Laboratory of Aerospace Power System, Nanjing Universityof Aeronautics \\ and Astronautics, Nanjing,210016, China \\ 2. AVIC Shenyang Engine Design \& Research Institute, Shenyang 110015, China \\ 3. The University of Strathclyde, Glasgow, UK \\ 4. Dogus University of Istanbul, Istanbul, Turkey \\ E-mail: benawra@gmail.com, jiqiang.wang@nuaa.edu.cn, hong.yue@strath.ac.uk,gdimirovski@dogus.edu.tr
}

\begin{abstract}
- this paper describes an effort to investigate and better define the capabilities of a modern mathematical solver in predicting the in on-design performance of a turbo fan engine PW4000. The results will validate the use of commercially available Object Oriented Programming (OOP) with $\mathrm{C}++$ software tools for these problems and lead to a better understanding of the flow phenomenon within the inlet to the outlet in the engine. Better engine designs that enhance design-point operation and improve performance could result once confidence is gained in applying performance analysis tools to the component section of the PW4000 engine design process.
\end{abstract}

Key Words: Turbofan engine; PW4000; Design point; performance cycle analysis

\section{INTRODUCTION}

Jet engines are type of gas turbines that are used to generate a high-speed jet for propulsive purposes. It's driven and discharges a high-speed moving jet of fluid to generate thrust in accordance to Newton's Third Law of Motion. Examples of gas turbines being used for aircraft propulsion applications include turboprops, turbojets, turbofans, and ramjets. In general a gas turbine consists of an upstream compressor coupled to a downstream turbine, and a burner in between [1]. These components compromises the heart of a gas turbine, e.g. gas generator.

Turbofan engines are found on commercial airliners around the world and have revolution the way we travel. The turbofan engine functions by the way of a thermodynamic cycle where air is ingested into the engine, compressed, combusted, expanded, and exhausted from the engine creating thrust to propel the vehicle. These five steps are carried out by five major engine components: the fan, compressor (low and high pressure), combustor (or combustion chamber), turbine (high and low pressure), and exhaust nozzle [2]. They were designed as a compromise between the turboprop and turbojet engines. A turbo engine induces a large internal propeller and two streams of air flowing through the engine. The primary

$\uparrow$ We wish to acknowledge the support of the Natural Science Foundation of Jiangsu Province (No. BK20140829); Jiangsu Postdoctoral Science Foundation (No.1401017B); and the Scottish Government which funded this project through the Royal Society of Edinburgh in partnership with the NNSFC; Fund for Science of Dogus University stream travels through all the components like a turbojet engine, while the secondary air passes through the fan and is either ducted outside through a second nozzle identified as the cold nozzle or may mix with hot gases leaving the turbines both are expelled from a single nozzle. The engines have a better performance, greater fuel economy than turbo jet at low power setting, low speed, and low altitude. High Bypass ratio turbofan jet engines like the PW4000 are found in large commercial airliners. The Bypass ratio is now 5:1 or larger. The subsonic speed, high-bypass turbofans are more fuel efficient and quieter than other types of jet engines. (Figure 1) shows an example how a high bypass turbofan engine looks like.



Figure 1. PW4000 engine

\subsection{ENGINE CYCLE AND STATION NUMBERING}

Some certain specific points along the engine axial profile are identified by station number to provide ease of reference for items such as component locations. (Figure 2) illustrates the schematic diagram configuration of the PW4000 engine and the station numbering for each component. The station numbers of each component will be used throughout the analysis in this research, including the parametric cycle analysis.

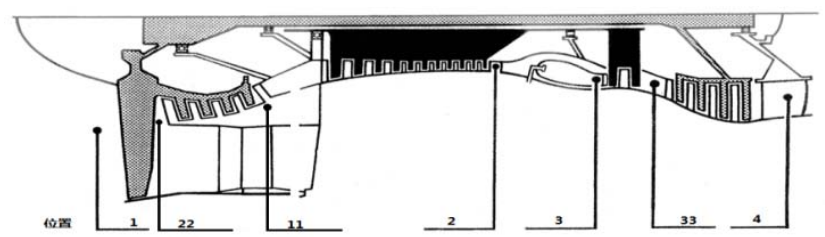

Figure 2 Schematic diagram of a turbofan engine PW4000 


\section{ENGINE PERFORMANCE}

In describing the performance of a turbofan engine, it is helpful to define their important air-breathing engine performance parameters that are useful in aircraft propulsion. They are thrust, fuel consumption, and engine efficiencies. Each of these parameters is briefly discussed here and the detailed derivations of each term will be shown in both cycle analyses.

\subsection{THRUST}

The thrust is a mechanical force that is generated by a jet engine to move the aircraft through the air. For a propulsion system it must be in physical contact with a working fluid to produce thrust. Thrust depends on the amount of gas that is accelerated and on the difference in velocity of the gas through the engine. For the turbo fan engines the analysis for the total thrust is mathematically described in equation (2.1):

$$
F=\dot{m}_{\text {core }}\left(V_{9}-V_{0}\right)+\dot{m}_{\text {bypass }}\left(V_{22}-V_{0}\right)
$$

where $\mathrm{F}$ is the Thrust force, $m_{\text {core }}$ is Core Mass Flow, $m_{\text {bypass }}$ is Bypass Mass Flow, and $V_{9}$ is Nozzle Exit Velocity, $V_{22}$ Bypass Exit Velocity and $V_{0}$ Intake Velocity.

\subsection{SFC}

Specific fuel consumption (SFC) is the fuel flow rate divided by the output thrust or power. For long-range, civil aircraft engines, a low SFC is critical as the cost of fuel is typically 15 to 25 per cent of aircraft operating costs [3]. For the turbo fan engines analysis for the SFC is mathematically described as:

$$
S F C=\frac{3600 m_{f}}{F}
$$

Where 3600 Converts seconds to hours, $m_{f}$ is the Mass Fuel Flow and $\mathrm{F}$ is the Thrust force.

\section{PW4000 COMPONENT DESIGN PARAMETERS AND ANALYSIS}

To calculate the component performance parameters, unknown and known inlet and discharge conditions for each component must be determined. The unknown inlet and discharge conditions that need to be calculated are the pressure, temperature, Mach number, Mass Flow, Thrust and SFC. The PW4000 is an unmixed twin spool turbofan engine; the calculation is done according to the assembly of its components and cross-sectional model since it's a shown in Figure 3 and passing the parameters by parts of the engine in Figure 4.

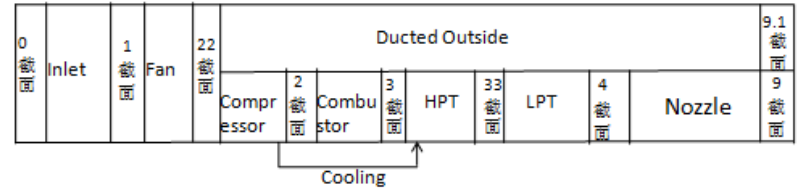

Figure 3 PW4000 Engine Components and Cross-sectional model.

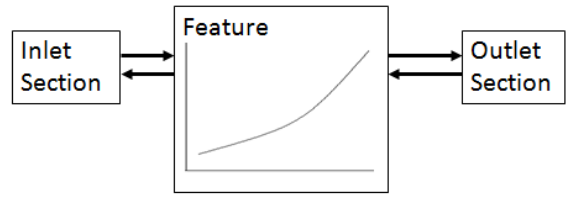

Figure 4 Passing Parameters by Parts.

\subsection{MASS FLOW FUNCTION}

The mass flow parameter (MFP) is mainly based on the law of conservation of mass. It has a combination of mass flow per unit area with the perfect gas law, Mach number, sound speed, and equations for total temperature and pressure [1]. We consider the equation (3.1) for the mass flow rate:

$$
\dot{m}=K \frac{A p^{*} q(\lambda)}{\sqrt{T^{*}}}
$$

Where $\mathrm{m}$ is the Mass flow Rate $(\mathrm{kg} / \mathrm{s}), K$ is Air/gas Coefficient, A is Section Area $\left(M^{2}\right), p^{*}$ is Total Pressure $(\mathrm{Pa}), T^{*}$ is Total Temperature $(\mathrm{K})$ and $q(\lambda)$ is Flow Density.

\subsection{INLET/INTAKE SECTION}

In this section of the engine there is no exchange of heat and kinetic energy occurrence if on ground, the total pressure and total temperature for this expression is mathematically described as:

$$
\begin{gathered}
T_{0}^{*}=T_{0}(3.2) \\
P_{0}^{*}=P_{0}(3.3) \\
P_{1}^{*}=\sigma_{i} P_{0}^{*}(3.4) \\
T_{1}^{*}=T_{0}^{*}(3.5)
\end{gathered}
$$

Where $P^{*}$ Total Pressure, $T^{*}$ is Total Temperature, $P$ Static Pressure, $T$ is Static Temperature and $\sigma_{i}$ is Inlet Pressure Recovery Coefficient.

\subsection{FAN}

It has two outlets, one outlet correspond to the inlet of the Bypass, the other corresponds to the compressor and has lower pressure ratio $\left(\pi_{f}\right)$ compared to core compressors [4]. The analysis for the output of the fan is mathematically described as:

The quantity of air flow that goes into the Bypass is given by:

$$
\begin{aligned}
& \dot{m}=\dot{m}_{c}+\dot{m}_{b} \\
& \dot{m}_{b}=\beta \dot{m}_{c}
\end{aligned}
$$


Make $m_{c}$ the subject in Equation (3.6) and substitute to Equation (3.7) given by

$$
\dot{m}_{b}=\beta\left(\dot{m}-\dot{m}_{b}\right)
$$

The quantity of air flow that goes into the Core is given by

$$
m_{c}=m-m_{b}(3.9)
$$

Make the $m_{b}$ the subject in Equation (3.9) which gives Equation (3.10) and substitute it to Equation (3.6) which gives Equation (3.10)

$$
\begin{aligned}
& \dot{m}_{b}=\dot{m}-\dot{m}_{c} \\
& \dot{m}=\dot{m}_{c}+\beta \dot{m}_{c}
\end{aligned}
$$

Finally make $m_{c}$ the subject in Equation (3.11) which gives the airflow through the Core given by

$$
\dot{m}_{c}=\frac{\dot{m}}{(1+\beta)}(3.12)
$$

The analysis for the fan outlet to the Bypass inlet section is mathematically described as:

$$
\begin{gathered}
\Delta \mathrm{s}=C_{p} \ln \frac{T_{22 i}^{*}}{T_{1}^{*}}-R \ln \pi_{f 2}^{*}=0 \\
C_{p} \ln T_{22 i}^{*}=C_{p} \ln T_{1}^{*}+R \ln \pi_{f 2}^{*}(3.15)
\end{gathered}
$$

We define;

$$
\Phi_{1}^{*}=C_{p} \ln T_{1}^{*}
$$

We can get $T_{22 i}^{*}$ in Equation (3.17) given by

$$
\begin{gathered}
\Phi_{22 i}^{*}=\Phi_{1}^{*}+R \ln \pi_{f 2}^{*} \Rightarrow T_{22 i}^{*}(3.17) \\
h_{22 i}^{*}=C_{p} T_{22 i}{ }^{*}
\end{gathered}
$$

Once we get the value of $T_{22 i}^{*}$ from Equation (3.17) we get $h_{22 i}^{*}$ in Equation (3.18) and since the Outer Fan Efficiency is given and $C_{p}$ is not constant we can get $T_{22}^{*}$ given by

$$
\begin{gathered}
\eta_{f 2}^{*}=\frac{h_{22 i}^{*}-h_{1}^{*}}{h_{22}^{*}-h_{1}^{*}} \\
h_{22}^{*}=h_{1}^{*}+\frac{h_{2 i}^{*}-h_{1}^{*}}{\eta_{f 2}^{*}} \Rightarrow T_{22}^{*}
\end{gathered}
$$

The analysis for the fan outlet to the Compressor inlet section is mathematically described as:

$$
\begin{gathered}
P_{11}^{*}=\pi_{f 1}^{*} P_{1}^{*}(3.21) \\
\Delta \mathrm{s}=C_{p} \ln \frac{T_{11 i}^{*}}{T_{1}^{*}}-R \ln \pi_{f 1}^{*}=0 \\
C_{p} \ln T_{11 i}^{*}=C_{p} \ln T_{1}^{*}+R \ln \pi_{f 1}^{*}
\end{gathered}
$$

We define;

$$
\Phi_{1}^{*}=C_{p} \ln T_{1}^{*}(3.24)
$$

We can get $T_{11 i}^{*}$ in Equation (2.25) given by

$$
\Phi_{11 i}^{*}=\Phi_{1}^{*}+R \ln \pi_{f 1}^{*} \Rightarrow T_{11 i}^{*}(3.25)
$$

$$
h_{11 i}^{*}=C_{p} T_{11 i}^{*}(3.26)
$$

Once we get the value of $T_{11 i}^{*}$ from Equation (3.25) we get $h_{11 i}^{*}$ in Equation (3.26) and since the Inner Fan Efficiency is given and $C_{p}$ is not constant, we can get $T_{11}^{*}$ given by

$$
\begin{gathered}
\eta_{f 1}^{*}=\frac{h_{11 i}^{*}-h_{1}^{*}}{h_{11}^{*}-h_{1}^{*}}(3.27) \\
h_{11}^{*}=h_{1}^{*}+\frac{h_{11 i}^{*}-h_{1}^{*}}{\eta_{f 1}^{*}} \Rightarrow T_{11}^{*}
\end{gathered}
$$

\subsection{BYPASS}

The analysis for the Bypass section is mathematically described as:

$$
\begin{gathered}
P_{91}{ }^{*}=\sigma_{b} P_{22}{ }^{*} \\
T_{91}^{*}=T_{22}^{*}
\end{gathered}
$$

\subsection{COMPRESSOR}

The analysis for the Compressor section is mathematically described as:

$$
\begin{gathered}
P_{2}^{*}=\pi_{c h}{ }^{*} P_{11}{ }^{*} \\
\Delta \mathrm{s}=C_{p} \ln \frac{T_{2 i}^{*}}{T_{11}^{*}}-R \ln \pi_{c h}^{*}=0 \\
C_{p} \ln T_{2 i}^{*}=C_{p} \ln T_{11}^{*}+R \ln \pi_{C}^{*}
\end{gathered}
$$

We define;

$$
\Phi_{11}^{*}=C_{p} \ln T_{11}^{*}
$$

We can get $T_{2 i}^{*}$ in Equation (3.31) given by

$$
\begin{array}{r}
\Phi_{2 i}^{*}=\Phi_{11}^{*}+R \ln \pi_{C}^{*} \Rightarrow T_{2 i}^{*} \\
h_{2 i}^{*}=C_{p} T_{2 i}^{*}(3.36)
\end{array}
$$

Once we get the value of $T_{2 i}^{*}$ from Equation (3.35), we can get $h_{2 i}^{*}$ from Equation (3.36) and since the Efficiency is given and $C_{p}$ is not constant we can get $T_{2}^{*}$ given by

$$
\begin{gathered}
\eta_{c h}^{*}=\frac{h_{2 i}^{*}-h_{11}^{*}}{h_{2}^{*}-h_{11}^{*}}(3.37) \\
h_{2}^{*}=h_{11}^{*}+\frac{h_{2 i}^{*}-h_{11}^{*}}{\eta_{c h}^{*}} \Rightarrow T_{2}^{*}
\end{gathered}
$$

\subsection{COMBUSTION CHAMBER}

In the combustor, the fuel is mixed with the air and burned to add energy to the primary gas path. The outer walls are constructed of segments with holes that permit air to enter the chamber for combustion, dilution, and cooling [5].

$$
P_{3}^{*}=\sigma P_{2}^{*}(3.39)
$$

The following procedures for this section is given by Since $T_{3}^{*}$ is given, we can get $h_{3}^{*}$ from Equation (2.35):

$$
h_{3}^{*}=C_{p} T_{3}^{*}(3.40)
$$


First we need to get the $C_{p}$ from Figure (3.3) and substitute in Equation (3.40)

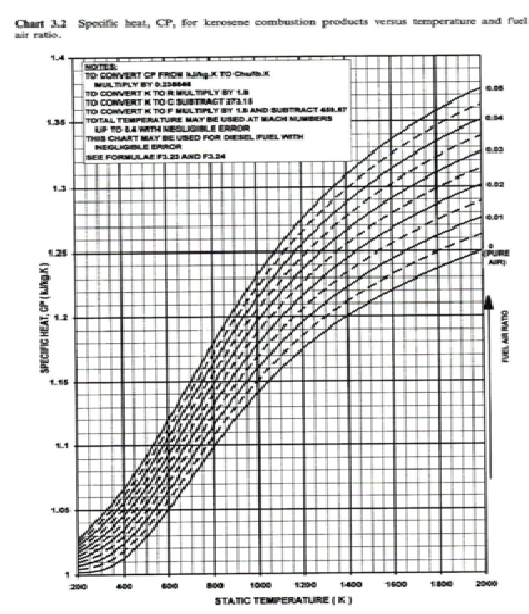

Figure 3.3 Specific heat $C_{p}$, for kerosene combustion products versus temperature and fuel air ratio [4].

The quantity of air flow that goes into the combustor chamber is given by

$$
\dot{m}_{2}=\dot{m}_{1}+\dot{m}_{f}(3.41)
$$

Since burner efficiency $\eta_{b}^{*}$ and $\left(\mathrm{LHV}=43.124 \times 10^{6}\right)$ we can calculate the Fuel mass $m_{f}$ In Equation (3.42)

$$
\eta_{b}{ }^{*}=\frac{\dot{m}_{2} h_{3}^{*}-\dot{m}_{1} h_{2}^{*}}{\dot{m}_{f} L H V}
$$

By doing further simplification from Equation (3.42) we

finally get the mass fuel ( $\left.m_{f}\right)$ in Equation (3.43) since we have all the data related to this equation is given by

$$
\dot{m}_{f}=\frac{\dot{m}_{2}\left(h_{3}^{*}-h_{2}^{*}\right)}{\eta_{b}{ }^{*} L H V-h_{3}^{*}}
$$

Once we get $\dot{m}_{f}$ from Equation (3.43) we substitute to the value in Equation (3.41) to give us Combustor outlet mass flow $\left(\dot{m}_{2}\right)$.

\subsection{HIGH PRESSURE TURBINE}

The quantity of air flow that goes into the HPT is given by:

$$
\dot{m}_{\text {Turbine }}=\dot{m}_{2}+\dot{m}_{\text {cooling }}
$$

Where $\dot{m}_{2}$ we get from Equation (3.37) in the combustion chamber analysis; First we need to calculate the HPT Pressure Ratio $\left(\pi_{t h}{ }^{*}\right)$, since the turbines require extra power to generate the aircraft and also to balance the power with the HPC in the engine. We can get the value in Equation (3.45) where we can get the Specific heat $(\gamma)$ from Figure (3.4) $\dot{m}_{2} h_{3}^{*}\left(1-\frac{1}{\pi_{t h}^{* \frac{\gamma-1}{\gamma}}}\right)-$ power $=50000+\frac{m_{2} h_{2}^{*}\left(\pi_{c h}^{* \frac{\gamma}{\gamma-1}}-1\right)}{\eta_{c h}^{*}}$

(3.45)

The equation above shows the power generated by the HPT that is used to drive HPC to provide a power balance to the shaft. The 50000J in the Equation above represents the work of the fuel pump that pumps the fuel to mix with the air in the combustion chamber. Finally we get the pressure ratio for the HPT from Equation (3.45), given as

$$
\left(\pi_{t h}^{*}=3.9\right)
$$

The analysis for the HPT section is mathematically described as:

$$
\begin{gathered}
P_{33}{ }^{*}=\pi_{t h}{ }^{*} P_{3}^{*} \\
\Delta \mathrm{s}=C_{p} \ln \frac{T_{33 i}^{*}}{T_{3}^{*}}-R \ln \pi_{t h}^{*}=0 \\
C_{p} \ln T_{33 i}^{*}=C_{p} \ln T_{3}^{*}-R \ln \pi_{t h}^{*}
\end{gathered}
$$

We define;

$$
\Phi_{33}^{*}=C_{p} \ln T_{33}^{*}
$$

We can get $T_{33 i}^{*}$ in Equation (3.46) given by

$$
\begin{gathered}
\Phi_{33 i}^{*}=\Phi_{33}^{*}-R \ln \pi_{t h}^{*} \Rightarrow T_{33 i}^{*} \\
h_{33 i}^{*}=C_{p} T_{33 i}^{*}(2.51)
\end{gathered}
$$

Once we get the value of $T_{33 i}^{*}$ from Equation (3.50), we can get $h_{33 i}^{*}$ from Equation (3.51) and since the Efficiency is given and $C_{p}$ is not constant we can get $T_{33}^{*}$ given by

$$
\begin{gathered}
\eta_{t h}^{*}=\frac{h_{3}^{*}-h_{33}^{*}}{h_{3}^{*}-h_{33 i}^{*}}(3.52) \\
h_{33}^{*}=h_{3}^{*}-\left(h_{3}^{*}-h_{33 i}^{*}\right) \eta_{t h} \Rightarrow T_{33}^{*}
\end{gathered}
$$

\subsection{LOW PRESSURE TURBINE}

The analysis for the LPT section is mathematically described as:

The quantity of air flow that goes into the LPT is given by

$$
\dot{m}_{2}=\dot{m}_{1}(3.54)
$$

First we need to calculate the LPT Pressure Ratio $\left(\pi_{t l}{ }^{*}\right)$, also to balance the power with the Fan in the engine. We can get the value in Equation (3.55) where we can get the Specific heat $(\gamma)$ from Figure (3.4)

$\dot{m}_{2} h_{33}^{*}\left(1-\frac{1}{\pi_{t l}^{*} \frac{\gamma-1}{\gamma}}\right) \eta_{t l}^{*}=\frac{\dot{m}_{1} h_{11}^{*}\left(\pi_{f 1}^{* \frac{\gamma-1}{\gamma}}-1\right)}{\eta_{f 1}^{*}}+\frac{\dot{m}_{2} h_{22}^{*}\left(\pi_{f 2}^{*} \frac{\gamma-1}{\gamma}-1\right)}{\eta_{f 2}^{*}}$

The equation above shows the power generated by the LPT that is used for two parts, one part is used to drive the fan and the other is used to drive the LPC to provide a 
power balance to the shaft. Finally we get the pressure ratio for the LPT from Equation (3.55), given as

$$
\left(\pi_{t l}^{*}=4.23\right)
$$

The analysis for the LPT section is mathematically described as:

$$
\begin{gathered}
P_{4}^{*}=\pi_{t l}{ }^{*} P_{33}{ }^{*}(3.56) \\
\Delta \mathrm{s}=C_{p} \ln \frac{T_{4 i}^{*}}{T_{33}^{*}}-R \ln \pi_{t l}^{*}=0 \\
C_{p} \ln T_{4 i}^{*}=C_{p} \ln T_{33}^{*}-R \ln \pi_{t l}^{*}
\end{gathered}
$$

We define;

$$
\Phi_{4 i}^{*}=C_{p} \ln T_{4 i}^{*}
$$

We can get $T_{4 i}^{*}$ in Equation (3.60) given by

$$
\begin{gathered}
\Phi_{4 i}^{*}=\Phi_{33}^{*}-R \ln \pi_{t l}^{*} \Rightarrow T_{4 i}^{*} \text { (3.60) } \\
h_{4 i}^{*}=C_{p} T_{4 i}^{*}
\end{gathered}
$$

Once we get the value of $T_{4 i}^{*}$ from Equation (3.60) we can get $h_{4 i}^{*}$ from Equation (3.61) and since the Efficiency is given and $C_{p}$ is not constant we can get $T_{4}^{*}$ given by

$$
\begin{array}{r}
\eta_{t l}^{*}=\frac{h_{33}^{*}-h_{4}^{*}}{h_{33}^{*}-h_{4 i}^{*}} \text { (3.62) } \\
h_{4}^{*}=h_{33}^{*}-\left(h_{4 i}^{*}-h_{33}^{*}\right) \eta_{t l}^{*} \Rightarrow T_{4}^{*}
\end{array}
$$

\subsection{NOZZLE}

. The analysis for the Nozzle section is mathematically described as:

$$
\begin{gathered}
P_{9}^{*}=\sigma_{e}^{*} P_{4}^{*} \text { (3.64) } \\
T_{9}^{*}=T_{4}^{*} \text { (3.65) }
\end{gathered}
$$

The Nozzle exit velocity is given by

$$
V_{9}=\lambda_{9} \sqrt{\frac{2}{\gamma+1} R T_{4}^{*}}
$$

Where we can get the Specific heat $(\gamma)$ from Figure (3.4) and $\left(\lambda_{9}\right)$ we get it from Equation (3.8)

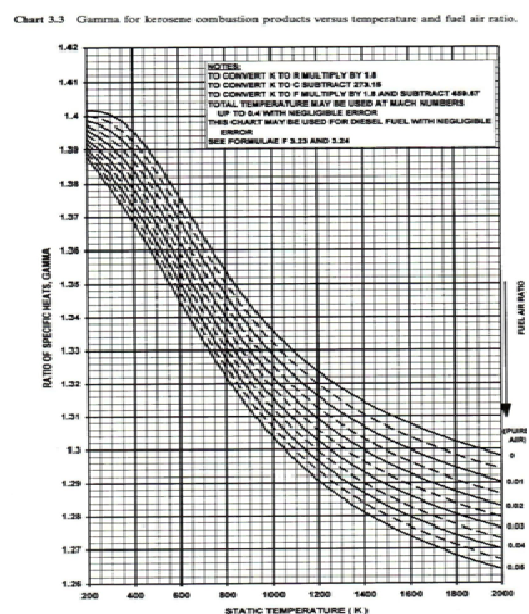

Figure 5 Gamma for kerosene combustion products versus temperature and fuel air ratio [4].

\section{PW4000 ENGINE GEOMETRY CALCULATION}

According to the PW4000 engine stations in Figure 3, the Area $(A)$ calculation for each section of the engine is mathematically described as

$$
A=\pi\left(\frac{d}{2}\right)^{2}-\pi\left(\frac{d}{2 B}\right)^{2}
$$

Where $d$ is the component diameter and $B$ is Taking over the hub.

$$
\dot{m}=K \frac{A p^{*} q(\lambda)}{\sqrt{T^{*}}}
$$

Substitute the value $q(\lambda)$ after calculating from Equation (4.2) into Equation (4.3), since $(\mathrm{k}=1.4)$ we can calculate $\lambda$ given by

$$
q(\lambda)=\left(\frac{k+1}{2}\right)^{\frac{1}{k-1}} \lambda\left(1-\frac{k-1}{k+1} \lambda^{2}\right)^{\frac{1}{k-1}}
$$

Finally we can calculate the Mach number by substituting the value $\lambda$ from Equation (4.3) into Equation (4.4) given by

$$
M_{a}=\lambda \sqrt{\frac{2}{(k+1)-(k-1) \lambda^{2}}}
$$

\section{RESULTS}

Table 1 PW4000Engine Cross-sectional Performance

\begin{tabular}{|l|c|c|c|c|}
\hline \multicolumn{1}{|c|}{ Section } & $\begin{array}{c}\text { Mass Flow } \\
(\mathrm{kg} / \mathrm{s})\end{array}$ & $\begin{array}{c}\text { Total Temperature } \\
(\mathrm{K})\end{array}$ & $\begin{array}{c}\text { Total Pressure } \\
(\mathrm{Pa})\end{array}$ & Mach Number \\
\hline INTAKE & 774.07 & 288.1 & 101325 & 0.000 \\
\hline FAN INLET & 774.07 & 288.1 & 100312 & 0.526 \\
\hline BYPASS INLET & 645.06 & 338.6 & 166518 & 0.319 \\
\hline BYPASS OUTLET & 645.06 & 338.6 & 161522 & 0.865 \\
\hline $\begin{array}{l}\text { COMPRESSOR } \\
\text { INLET }\end{array}$ & 129.01 & 399.5 & 258102 & 0.357 \\
\hline
\end{tabular}

\begin{tabular}{|l|c|c|c|c|}
\hline COMBUSTOR INLET & 116.11 & 838.5 & 2883001 & 0.165 \\
\hline $\begin{array}{l}\text { COMBUSTOR } \\
\text { OUTLET }\end{array}$ & 118.76 & 1574.2 & 2796511 & 0.101 \\
\hline $\begin{array}{l}\text { HIGH PRESSURE } \\
\text { TURBINE OUTLET }\end{array}$ & 131.66 & 1138.9 & 716441 & 0.322 \\
\hline $\begin{array}{l}\text { LOW PRESSURE } \\
\text { TURBINE OUTLET }\end{array}$ & 131.66 & 834.2 & 169219 & 0.368 \\
\hline NOZZLE OUTLET & 131.66 & 834.2 & 162450 & 0.882 \\
\hline
\end{tabular}


Table 2 PW4000Engine Cross-sectional Area

\begin{tabular}{|l|c|}
\hline \multicolumn{1}{|c|}{ Engine Section } & $\begin{array}{c}\text { Area } \\
\left(M^{2}\right)\end{array}$ \\
\hline FAN INLET & 4.189 \\
\hline BYPASS INLET & 3.4 \\
\hline $\begin{array}{l}\text { COMPRESSOR } \\
\text { INLET }\end{array}$ & 0.433 \\
\hline $\begin{array}{l}\text { COMPRESSOR } \\
\text { OUTLET }\end{array}$ & 0.105 \\
\hline
\end{tabular}

\begin{tabular}{|l|c|}
\hline $\begin{array}{l}\text { HIGH PRESSURE } \\
\text { TURBINE INLET }\end{array}$ & 0.25 \\
\hline $\begin{array}{l}\text { HIGH PRESSURE } \\
\text { TURBINE OUTLET }\end{array}$ & 0.302 \\
\hline $\begin{array}{l}\text { LOW PRESSURE } \\
\text { TURBINE OUTLET }\end{array}$ & 0.969 \\
\hline NOZZLE & 0.598497 \\
\hline
\end{tabular}

Table 3 PW4000Engine Performance Parameters

\begin{tabular}{|c|c|c|c|}
\hline $\begin{array}{c}\text { SFC } \\
(\mathrm{Kg} / \mathrm{N} / \mathrm{h})\end{array}$ & $\begin{array}{c}\text { MASS FUEL } \\
(\mathrm{kg} / \mathrm{s})\end{array}$ & $\begin{array}{c}\text { THRUST } \\
(\mathrm{N})\end{array}$ & $\begin{array}{c}\text { NOZZLE VELOCITY } \\
\left(V_{9}\right)\end{array}$ \\
\hline $3.839660 \mathrm{E}-002$ & 2.652747 & 248717.089114 & 461.698739 \\
\hline
\end{tabular}

\section{CONCLUSION}

The research objective of this paper is to transfer the parameters from the inlet section to the outlet section for each component containing in the PW4000 engine. Using the given design parameters to calculate the total thrust, SFC, Section Area, Mach number, Mass flow etc. in the ground state of the pneumatic test each section of the thermal parameters in the engine. The results provided are then used to search for possible operating range for each engine component for an optimum design choice.

We got the results for every cross-sectional Mach number of the PW4000 engine. For the Fan inlet the Mach number range given by Rolls Royce book is from $0.55 \sim 0.65$ [4], but referring to the results in Table (6.1) the Mach number for the Fan inlet is 0.526 which lies close to 0.55 .

The Bypass exit Mach number range given by Rolls Royce book is from 0.3 0.35 [4]. But referring to the results in Table (6.1) the Mach number for the Bypass Outlet is 0.865 which is above the range.

The Compressor inlet Mach number range according to the book is given from 0.4 0.6 [4]. Referring to the results in Table (6.1) the Mach number for the compressor inlet is 0.357 which lies close to 0.4 .

The Compressor Exit Mach number range according to the book is given from $0.2 \sim 0.35$ [4]. Referring to the results in Table (6.1) the Mach number for the compressor inlet is 0.165 which lies close to 0.2 .
The Turbine inlet Mach number range according to the book is equal to 0.2 [4]. Referring to the results in Table (6.1) the Mach number for the compressor inlet is 0.101 which is lower than the required range.

The Turbine exit Mach number according to the book is approximately equal to 0.3 but less than 0.55 [4]. According to the results in Table (6.1) the Mach number for the turbine outlet lies between the ranges given.

\section{REFERENCES}

[1] KA HENG LIEW. Aerothemodynamic cycle analysis of a dual-spool, separate-exhaust Turbofan Engine with an interstage turbine burner[D]. Michigan: Michigan Technological University, 2006.

[2] Colin Kling. Process Description: How a Turbofan Engine Works[J]. ENGL. 2011, 3.

[3] Rolls Royce. The Jet Engine [M]. $5^{\text {th }}$. UK, 1996. 76.

[4] P.P Walsh, P.Fletcher. Gas Turbines Performance[M]. $2^{\text {nd }}$.Oxford :Blackwell Publishing Company, 2004. 159 215.

[5] Treager. Aircraft Gas Turbine Engine Technology[M]. $3^{\text {rd }}$. India:McGraw Hill Education, 2002. 444 454. 